\title{
Adaptive Cardiac Resynchronization Therapy Effect on Electrical Dyssynchrony (aCRT- ELSYNC): a randomized controlled trial
}

Kazi T. Haq ${ }^{1}$, PhD, Nichole M. Rogovoy ${ }^{1}$, BS, Jason A. Thomas ${ }^{1,2}$, BS, Christopher Hamilton $^{1}$, BA, Katherine J. Lutz ${ }^{1}$, MD, Ashley Wirth ${ }^{1}$, BS, Aron B. Bender ${ }^{1,3}$, MD, David M. German $^{1,3}, \mathrm{MD}, \mathrm{MPH}$, Ryle Przybylowicz ${ }^{1}, \mathrm{MD}$, Peter van Dam ${ }^{4}, \mathrm{PhD}$, Thomas A. Dewland ${ }^{1,5}$, MD, ${ }^{2}$ Khidir Dalouk ${ }^{1,6}$, MD, Eric Stecker ${ }^{1}$, MD, Babak Nazer ${ }^{1}$, MD, Peter M. Jessel ${ }^{1,6}$, MD, Karen S. MacMurdy ${ }^{1,6}$, MD, Ignatius Gerardo E. Zarraga ${ }^{1,6}$, MD, Bassel Beitinjaneh ${ }^{1}$, MD, Charles A. Henrikson ${ }^{1}$, MD, MPH, Merritt Raitt ${ }^{1,6}$, MD, Cristina Fuss ${ }^{7}$, MD, Maros Ferencik ${ }^{1}$, MD, PhD, MCR, Larisa G. Tereshchenko ${ }^{1}$, MD, PhD, FHRS, CCDS.

${ }^{1}$ Knight Cardiovascular Institute, Oregon Health \& Science University, Portland, OR;

${ }^{2}$ University of Washington, Seattle, WA; ${ }^{3}$ University of California Los Angeles, Los Angeles, CA, ${ }^{4}$ Peacs BV, Arnhem, the Netherlands, ${ }^{5}$ University of California San Francisco, San Francisco, CA, ${ }^{6}$ VA Portland Health Care System, Portland, OR; ${ }^{7}$ Department of Diagnostic Radiology, Oregon Health \& Science University, Portland, OR.

Correspondence: Larisa Tereshchenko, 3181 SW Sam Jackson Park Rd; UHN62; Portland, OR, 97239. E-mail:tereshch@ohsu.edu.

\section{Brief title: aCRT-ELSYNC RCT results}

Clinical Trial Registration-URL: www.ClinicalTrials.gov Identifier: NCT02543281 
medRxiv preprint doi: https://doi.org/10.1101/2020.09.14.20194415; this version posted September 15, 2020. The copyright holder for this

\begin{abstract}
Introduction: Adaptive cardiac resynchronization therapy (aCRT) is known to have clinical benefits over conventional CRT; however, their effects on the electrical dyssynchrony have not been compared.
\end{abstract}

Methods: We conducted a double-blind, randomized controlled trial in patients receiving CRT for routine clinical indications. Participants underwent cardiac computed tomography and 128-electrodes body surface mapping. We measured electrical dyssynchrony on the epicardial surface using noninvasive electrocardiographic imaging (ECGI) before and 6 months post-CRT. Ventricular electrical uncoupling (VEU) was calculated as the difference between the mean left ventricular (LV) and right ventricular (RV) activation times. An electrical dyssynchrony index (EDI) was computed as the standard deviation of local epicardial activation times.

Results: We randomized 27 participants (mean age $64 \pm 12$ y; 34\% female; $53 \%$ ischemic

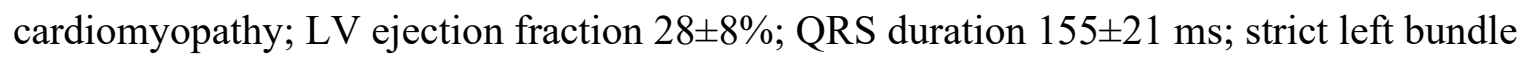
branch block (LBBB) in 13\%). In atypical LBBB ( $\mathrm{n}=11 ; 41 \%)$ with $\mathrm{S}$-waves in $\mathrm{V}_{5}-\mathrm{V}_{6}$, conduction block occurred in the anterior RV, as opposed to the interventricular groove in those who met the strict LBBB criteria. As compared to baseline, VEU reduced post-CRT in aCRT (median reduction 18.9(interquartile range 4.3-29.2 ms; $\mathrm{P}=0.034$ ), but not in conventional CRT (21.4(-30.0 to $49.9 \mathrm{~ms} ; \mathrm{P}=0.525)$ group. There were no differences in the degree of change in VEU and EDI indices between treatment groups.

Conclusion: The effect of aCRT and conventional CRT on electrical dyssynchrony is largely similar. Further studies are needed to investigate if atypical LBBB with prominent $\mathrm{S}$ wave in $\mathrm{V}_{5-}$ $\mathrm{V}_{6}$ responds to His bundle pacing.

Keywords: CRT; heart failure; dyssynchrony; AV optimization 
medRxiv preprint doi: https://doi.org/10.1101/2020.09.14.20194415; this version posted September 15, 2020. The copyright holder for this

\section{Introduction}

The adaptive cardiac resynchronization therapy (aCRT) algorithm has been developed to optimize CRT delivery by avoiding right ventricular (RV) pacing and providing concomitant dynamic atrioventricular (AV) and ventriculo-ventricular (VV) adjustments through the measurement of intracardiac conduction parameters. ${ }^{1}$ A randomized controlled trial comparing aCRT and conventional CRT showed that aCRT is safe and at least as effective as conventional $\mathrm{CRT}^{2}$ A higher percentage of left ventricular (LV) pacing was associated with superior clinical outcomes, including decreased risk of death, heart failure (HF) hospitalizations, ${ }^{3}$ and 30-day readmissions. ${ }^{4}$ Further analysis comparing aCRT to the historic conventional CRT controls showed that the proportion of clinical responders to aCRT was higher by $12 \% .{ }^{5}$ Notably, aCRT reduced the occurrence of atrial fibrillation (AF) by continuously adjusting AV intervals. ${ }^{6-9}$

However, aCRT's impact on electrical dyssynchrony is not entirely clear. Experimental studies in left bundle branch block (LBBB)-failing hearts showed that bi-ventricular (BiV) pacing, but not LV pacing, decreased electrical dispersion. ${ }^{10}$ Some previous randomized controlled trials that compared LV and BiV pacing showed a similar benefit for BiV and LV CRT. ${ }^{11-13}$ Further measurements aCRT's effect on electrical dyssynchrony, such as epicardial activation map analysis and novel vectorcardiographic (VCG) metrics, have not previously been assessed. A better understanding of the mechanisms behind aCRT is essential for further improvement in CRT delivery and clinical outcomes.

To investigate the effect of aCRT on electrical dyssynchrony, we conducted a randomized controlled trial (RCT) “Adaptive CRT Effect on Electrical Dyssynchrony” (aCRT-ELSYNC; ClinicalTrials.gov Identifier: NCT02543281). We hypothesized that (1) aCRT (as compared to conventional CRT) provides a superior degree of reduction of electrical dyssynchrony 6-months 
medRxiv preprint doi: https://doi.org/10.1101/2020.09.14.20194415; this version posted September 15, 2020. The copyright holder for this

post-CRT, and (2) surface ECG/VCG metric, sum absolute QRST integral (SAIQRST), ${ }^{14,15}$ is a superior estimate of electrical dyssynchrony as compared to QRS duration. The secondary objective was to determine if aCRT is associated with improvement in the quality of life and other clinically important outcomes.

\section{Method}

\section{Trial design}

We conducted a single-center, double-blind, 1:1 parallel-group assignment RCT. The study was approved by the Oregon Health \& Science University (OHSU) Institutional Review Board (IRB), and it was monitored by the Data and Safety Monitoring Board. All study participants signed written informed consent before entering the study. Study data were collected and managed using REDCap electronic data capture tools hosted at OHSU. ${ }^{16,17}$

Six weeks after trial commencement, the registry arm was added to include the study participants who failed the RCT eligibility criteria screening. Furthermore, in the fall of 2018, an initial exclusion criterion (previous or existing CRT system, implantable cardioverterdefibrillator (ICD), or pacemaker) was broadened to include individuals with a previously implanted single-chamber ICD if they had a documented history of ventricular pacing (VP) $<1 \%$ and an indication for CRT upgrade.

There were two study visits. The first was prior to CRT device implantation. The second visit was six months post-CRT implantation. Both visits included documentation of the medical history and use of medications, the quality of life assessment using the 36-Item Short Form Health Survey (SF-36) and Minnesota Living with Heart Failure Questionnaire (MLHFQ), recording of 12-lead Holter ECG at rest and during a 6-minute walk test, and body surface 
medRxiv preprint doi: https://doi.org/10.1101/2020.09.14.20194415; this version posted September 15, 2020. The copyright holder for this

potential mapping. Cardiac computed tomography (CT) scan or cardiac magnetic resonance

(CMR) study was performed once, before the device implantation. In addition, a copy of digital intracardiac electrograms was saved during CRT implantation.

Echocardiography data and assessment of the New York Heart Association (NYHA) class data were obtained from the medical records.

\section{Eligibility criteria for study participants}

All OHSU patients who were scheduled for CRT device implantation at OHSU were considered for participation.

Inclusion criteria were standard class I or class II indications for CRT pacemaker (CRT-P) or CRT-defibrillator (CRT-D) implantation in accordance with ACC/AHA/HRS guidelines, ${ }^{18}$ age $\geq$ 18 years, and willingness and ability to comply with the protocol.

Exclusion criteria were:

1) Presence of a permanent AF. AF was considered permanent when it was continuously present, and the physician and patient decided not to make any further attempts at rhythm control.

2) Previous/existing CRT system or pacemaker, or existing ICD if the amount of ventricular pacing was $>1 \%$.

3) Estimated glomerular filtration rate $(\mathrm{eGFR})<30 \mathrm{ml} / \mathrm{min}$.

4) Unstable angina, acute myocardial infarction (MI), coronary artery bypass graft (CABG) surgery, or percutaneous coronary intervention (PCI) within 30 days before enrollment.

5) Valvular heart disease with indications for valve repair or replacement.

6) Enrollment in any other interventional trial. 
7) Pregnancy.

8) Post-heart transplant status.

9) New NYHA class IV HF or progression to NYHA class IV HF within three months before enrollment.

10) Concomitant condition other than a cardiac disease that is associated with a higher likelihood of death during one year after enrollment.

11) Inability or unwillingness to cooperate or give written informed consent.

\section{Intervention}

The study participants were implanted with a commercially available, clinically indicated Medtronic CRT device with aCRT algorithm (Viva ${ }^{\mathrm{TM}}$ models DTBA1D4, DTBA1D1, DTBA1Q1, DTBA1QQ, DTBB1Q1, DTBB1QQ, DTBB1D1, DTBB1D4, or C6TR01). Any compatible lead could be implanted. LV lead location was selected at the discretion of the implanting electrophysiologist. The aCRT intervention arm had adaptive BiV and LV pacing programmed ON, while the conventional CRT control arm had nonadaptive CRT programmed ON.

\section{Randomization and blinding}

Study participants were randomized using a random stratified block, with assignment ratio 1:1, and two assignment strata: by sex (male vs. female) and cardiomyopathy type (ischemic vs. nonischemic). We used a random block size $(2,4$, or 6$)$ with allocation proportional to the elements of Pascal's triangle. A random seed was used, and the randomization list was created using the -ralloc- program in Stata version 13.1.

Randomization was enacted via sealed envelopes containing randomization assignments delivered to a Medtronic field representative/device technician who programmed the CRT device 
medRxiv preprint doi: https://doi.org/10.1101/2020.09.14.20194415; this version posted September 15, 2020. The copyright holder for this

immediately after the implantation. The participants, implanting team, and study investigators assessing outcomes were blinded to the intervention.

\section{Primary endpoints}

For the $1^{\text {st }}$ hypothesis, the primary endpoint was defined as a change in electrical dyssynchrony metrics measured on epicardial activation map and surface ECG six months postCRT, as compared to pre-CRT.

For the 2nd hypothesis, the primary endpoint was defined as a correlation between the surface ECG metrics of dyssynchrony (SAIQRST, in comparison to QRS duration and QRS area) and electrical dyssynchrony metrics measured on the epicardial activation map, assessed prior to CRT implantation.

\section{Building the epicardial activation map}

We employed an electrocardiographic imaging (ECGI) ${ }^{19,20}$ approach to build an epicardial activation map. ${ }^{21}$ For each study participant, we built two maps: before CRT implantation and six months post-CRT. Figure 1 shows the steps in data analysis. To obtain the solution of the inverse problem, we used the SCIRun problem-solving software developed at the Center for Integrative Biomedical Computing (University of Utah, UT, US) ${ }^{22}$.

The study participants underwent recording of unipolar ECG potentials on the body surface using the ActiveTwo biopotential measurement system (BioSemi, Amsterdam, the Netherlands) with $128 \mathrm{Ag} / \mathrm{AgCL}$ electrodes (4 panels of 32 electrodes; each panel is arranged as four strips of 8-electrodes; diameter of the ECG electrodes $5 \mathrm{~mm}),{ }^{23}$ sampling rate $16,384 \mathrm{~Hz}$ and bandwidth DC-3,200 Hz. The localization of the electrodes was performed using a three dimensional (3D) photography approach using PeacsKinect (Peacs BV, Arnhem, the Netherlands), as previously described. ${ }^{23}$ Immediately after the body potentials recording, participants underwent cardiac 
medRxiv preprint doi: https://doi.org/10.1101/2020.09.14.20194415; this version posted September 15, 2020. The copyright holder for this

imaging while wearing $\geq 5$ electrode markers for subsequent co-registration of torso images.

Body surface potentials were recorded twice: before CRT implant and 6 months post-implant.

Before CRT implantation, study participants underwent either non-contrast CT or CMR study. Non-contrast CMR used a Siemens TIM Trio 3 Tesla with VB17 software and Siemens Prisma Fit 3 Tesla scanner with E11C software. Prospectively ECG-triggered non-contrast 128slice cardiac CT (Philips iCT SP, Philips Medical Imaging, Cleveland, OH) images were acquired in mid to end-diastole with a slice thickness of $0.6 \mathrm{~mm}$ and in-plane resolution of $\sim 0.5$ mm. Two cardiologists (RP, MF) reviewed cardiac CT/CMR images and identified interventricular and atrioventricular grooves. Ventricular volumes were obtained in a semiautomatic fashion using commercially available software (IntelliSpace Portal; Philips Healthcare, Redmond, WA, US for CT; and CVI42; Circle Cardiovascular Imaging Inc., Calgary, Alberta, Canada for MRI).

We used the collected CT/MRI data to reconstruct the 3D mesh of the ventricle and torso. A semi-automated mesh generation algorithm ${ }^{23}$ (ITK-snap software, PICSL, United States) ${ }^{24}$ was applied to obtain the meshes (Figure 1). Each cardiac mesh was manually reviewed (KTH) to ensure a continuous segmentation of the epicardium of both ventricular chambers and exclude atria chambers. The torso meshes were also manually reviewed (KTH).

A normal sinus beat (baseline) or a paced beat (follow up) was selected for analyses. Wilson's central terminal (WCT) potential was calculated by averaging the potentials recorded by the electrodes placed in the three extremities (left arm, right arm, and left leg). The unipolar voltage at each of 128 torso electrodes was then calculated by subtracting WCT potential from the potential recorded by the torso electrode. 
medRxiv preprint doi: https://doi.org/10.1101/2020.09.14.20194415; this version posted September 15, 2020. The copyright holder for this

We used the boundary element solution provided by the 'BuildBEmatrix' in the forwardinverse toolkit in SCIRun. BuildFEMatrix inputs a finite element mesh with the conductivities set on each element. The output transfer matrix is a stiffness matrix based on the Galerkin method. The module used the ventricular mesh as the 'inner surface' and the surface built by $n$ number of electrodes on the torso as the 'outer surface.' Once the transfer matrix A was created, the next step was to solve the inverse problem for the epicardial potentials using the zero-order Tikhonov regularization scheme provided by the 'SolveInverseProblemWithTikhonov' in the SCIrun forward-inverse toolkit. We used the manual selection option provided in the module to select a range of solution constraint parameter $\gamma$ values. The selected $\gamma$ values warranted the formation of the "L" shaped curve ( known as "L-curve" approach ) when the residual norm and the weighted solution norm was plotted in a log-log plot. The resulting solution matrix provided the calculated unipolar epicardial electrograms (EGMs) at each node of the epicardial mesh. The resolution of the ventricular mesh was $3.2 \pm 1.1 \mathrm{~mm}$, with $3,961 \pm 658$ nodes.

Local activation time (LAT) was calculated as the time between a common reference point (body surface potential QRS onset) and the point of steepest downward slope (minimum $\mathrm{dV} / \mathrm{dt}$ ) of the epicardial EGM on each epicardial node within one-fifth of the cardiac cycle measured from the local absolute maximum of unipolar EGM signal (Figure 1C). Accuracy of automated LAT detection was manually verified by three investigators (KTH, KJL, AW) on a random sample of EGMs for each map. If inaccurate LAT was due to erroneous minimum $\mathrm{dV} / \mathrm{dt}$ detection, it was corrected. If an epicardial EGM did not display a morphology allowing a single accurate LAT identification, the corresponding epicardial node was removed. 
medRxiv preprint doi: https://doi.org/10.1101/2020.09.14.20194415; this version posted September 15, 2020. The copyright holder for this

\section{Electrical Dyssynchrony on Epicardial Activation Maps}

Electrical dyssynchrony on the epicardial activation map was quantified by the following metrics. ${ }^{25,26}$ The RV activation time (RVAT) was defined as the time between the earliest and the latest site of RV activation. The LV activation time (LVAT) was defined as the time between the earliest and the latest site of LV activation. The global total activation time (TAT) was defined as the time between the earliest and the latest site of the total ventricular epicardial activation. Ventricular electrical uncoupling (VEU) was measured as the difference between the mean LV and RV activation times. Positive VEU indicated LV uncoupling (delay) from the RV, whereas negative VEU indicated RV uncoupling (delay) from the LV. ${ }^{26}$ An electrical dyssynchrony index (EDI) was computed as the standard deviation of activation times throughout the entire ventricular epicardium $\left(E D I_{V}\right), \mathrm{LV}$ epicardium $\left(\mathrm{EDI}_{\mathrm{LV}}\right)$, and RV epicardium $\left(\mathrm{EDI}_{\mathrm{RV}}\right)$.

\section{Electrical Dyssynchrony Indices on Surface ECG and VCG}

Assessment of the baseline QRS duration and morphology (ventricular conduction abnormality) was performed using clinical 12-lead ECG recorded before CRT implant, stored in the electronic medical record.

For vectorcardiographic (VCG) analysis, to ensure adequate comparison of electrical dyssynchrony measured on surface ECG and epicardial activation maps, we constructed a 12lead ECG using recorded body surface potentials and analyzed the same cardiac beat. We identified the location of the $\mathrm{V}_{1}-\mathrm{V}_{6}$ electrodes in the nearest proximity of the expected precordial leads location (Supplemental Figure 1). Limb lead I was calculated as the difference of left arm right arm potentials. Lead II was calculated as the difference of left leg - right arm potentials, and lead III is the difference of left leg - left arm potentials. Kors transformation matrix was 
medRxiv preprint doi: https://doi.org/10.1101/2020.09.14.20194415; this version posted September 15, 2020. The copyright holder for this

used to transform the 12-lead to orthogonal XYZ ECG. Per study protocol, electrical dyssynchrony on surface ECG was measured by QRS duration and sum absolute QRST integral (SAIQRST). ${ }^{14,15}$ In addition, we measured QRS duration and QRS area ${ }^{27}$ as previously described. ${ }^{28,29}$

\section{Secondary clinical endpoints}

The secondary clinical endpoints were assessed by the research team members blinded to the randomization assignment. The clinical composite outcome was defined as worsened if a study participant (1) died from any cause, or (2) experienced HF hospitalization within six months post-CRT. In addition, secondary endpoints included quality of life assessment by the Minnesota Living with Heart Failure Questionnaire (MLHFQ) and 36-Item Short Form Survey (SF-36) questionnaire. The 6-minute walk distance was measured.

\section{Statistical analysis}

The planned sample size (32 participants) was estimated based on prior observational study data, ${ }^{30}$ reporting the distribution of EDI in CRT responders and non-responders.

We conducted an intention-to-treat analysis. Wilcoxon (Mann-Whitney) rank-sum exact test was used to compare continuous variables that were summarized as the median and interquartile range (IQR). Fisher's exact test was used to compare categorical variables. Wilcoxon matchedpairs signed-rank test was used to compare changes from the baseline to 6-months post-CRT. Spearman's correlation statistics were computed to study an association between epicardial and surface ECG measures of dyssynchrony. Two-sided exact $\mathrm{P}$-values were reported. $P<0.05$ was considered statistically significant. Statistical analyses were performed using STATA MP 16.1 (StataCorp LLC, College Station, TX). 


\section{Results}

\section{Study Population}

The study flowchart is shown in Figure 2. Enrollment in the study was completed between June $22^{\text {nd }}, 2015$, and October $10^{\text {th }}, 2018$. All study participants had LV lead successfully implanted within the epicardial venous system. Out of 32 enrolled participants, 27 were randomized, and five were included in the registry arm. All randomized participants, and 4 out of the 5 registry participants completed the 6-month follow-up visit procedures.

The clinical characteristics of the study participants are shown in Table 1. One-third of the participants were female, and approximately half had ischemic cardiomyopathy. Out of randomized participants, $15 \%(n=4)$ met strict LBBB criteria (broad notched or slurred $\mathrm{R}$ without $\mathrm{Q}$ and $\mathrm{S}$ waves in leads $\mathrm{I}, \mathrm{aVL}, \mathrm{V}_{5}$, and $\mathrm{V}_{6}$; intrinsicoid deflection in $\left.\mathrm{V}_{5}-\mathrm{V}_{6}>60 \mathrm{~ms}\right), 41 \%$ $(\mathrm{n}=11)$ met LBBB criteria used in the main CRT trials $\left(\mathrm{RsR}^{\prime}\right.$ in $\mathrm{V}_{6}$ and $\mathrm{rS} / \mathrm{QS}$ in $\left.\mathrm{V}_{1}-\mathrm{V}_{2}\right)$ and had prominent $\mathrm{S}$ waves in $\mathrm{V}_{5}-\mathrm{V}_{6}$, and $44 \%(\mathrm{n}=12)$ had IVCD with QRS duration above $150 \mathrm{~ms}$. Nearly all participants were on ACEI or ARBs and beta-blockers. Study groups were wellbalanced.

\section{Effect of aCRT on ventricular epicardial activation maps and electrical dyssynchrony}

At baseline, epicardial activation in a strict LBBB (Figure 3A and Supplemental Figure 2) manifested with RV breakthrough that began in the mid-RV and rapidly activated the entire RV, whereas LV activation was delayed. The line of conduction block corresponded to the interventricular groove. Epicardial activation in atypical LBBB with $\mathrm{S}$-waves in $\mathrm{V}_{5}-\mathrm{V}_{6}$ (Figure 4A and Supplemental Figure 3) differed from typical LBBB in two ways. First, the line of the conduction block was located more anteriorly, away from the interventricular groove, in the RV 
medRxiv preprint doi: https://doi.org/10.1101/2020.09.14.20194415; this version posted September 15, 2020. The copyright holder for this

vicinity. Second, the epicardial activation spreading from RV to LV involved apical LV segments before or at the same time as basal LV segments. Overall, the LV activation patterns were remarkably variable in study participants.

LV-only pacing in the aCRT arm presented with the earliest activation in the LV epicardium and gradual propagation of activation (Figure 3B). Bi-V pacing in the conventional CRT arm (Figure 4B) had two early activation centers, corresponding to RV and LV leads. Most lines of conduction block previously observed in sinus rhythm shifted or disappeared during ventricular pacing, suggesting the functional nature of the block (Figures 3-4). The electrical activation sequence was patent-specific.

At baseline, there were no differences in the dyssynchrony metrics between treatment groups (Table 2). Post-CRT, TAT, LVAT, and RVAT were reduced significantly and similarly in both groups. Baseline VEU ranged from negative 85 to positive $72 \mathrm{~ms}$, indicating that the study participants had dyssynchrony due to both LV and RV uncoupling, without significant differences between treatment groups. Post-CRT, VEU significantly decreased only in the aCRT group, but not in the conventional CRT arm. Post-CRT, aCRT significantly reduced RV uncoupling (Table 2). This is illustrated by changes in VEU in each study participant (Figure 5). Harmonious VEU reduction was observed in aCRT group, in contrast to the conventional CRT arm, demonstrating discordant and inconsistent changes in VEU. However, there was no statistically significant difference in the degree of VEU reduction between treatment groups.

Both aCRT and conventional CRT resulted in a significant reduction of both intra-ventricular and inter-ventricular dyssynchrony as measured by EDI indices, without differences between treatment groups (Table 2). 


\section{Effect of aCRT on surface ECG and VCG.}

QRS area and SAIQRST significantly decreased post-CRT in both groups, whereas QRS duration changes were borderline. However, no significant differences were found in QRS duration, QRS area, and SAIQRST between the two treatment groups at baseline or after therapy (Table 3).

\section{Correlation of the dyssynchrony measured on surface ECG and epicardial surface}

There was no statistically significant correlation between any of the epicardial and surface ECG measures of dyssynchrony was found in all (including registry) study participants at baseline (Supplemental Table 1).

\section{Secondary outcomes}

There were no deaths and HF hospitalizations during 6 months of follow-up. There were no differences in the 6-minute walk distance between treatment groups. Baseline and post-CRT 6minute walk distance did not differ either (Table 4). Overall, MLHFQ score improved from baseline [median 46(IQR 20-68)] to post-CRT [median 27(IQR 11-48); P=0.003]. However, there were no differences between treatment groups.

On average, role limitations due to physical health improved with CRT (from median 0 (IQR 0-63) to median 100 (IQR 0-100); $\mathrm{P}=0.004)$. The energy/fatigue score improved from a median 30(IQR 20-53) to median 55(IQR 35-70); $\mathrm{P}=0.004$. There was no pre- versus post- CRT difference in other SF-36 indicators and no difference in any SF-36 indicators between treatment groups (Table 4). 
medRxiv preprint doi: https://doi.org/10.1101/2020.09.14.20194415; this version posted September 15, 2020. The copyright holder for this

\section{Discussion}

Our double-blind RCT showed that the effect of aCRT and conventional CRT on electrical dyssynchrony is largely similar, with both significantly reducing electrical dyssynchrony overall. We did not find differences between aCRT and conventional CRT in the degree of reduction of LV and RV inter- and intraventricular electrical dyssynchrony 6-month post-CRT. However, only aCRT but not conventional CRT harmoniously reduced interventricular dyssynchrony by reducing RV uncoupling. The observed differences in the effect of aCRT and conventional CRT on interventricular dyssynchrony suggest that a reduction of RV uncoupling together with adaptive AV optimization are the mechanisms behind the previously reported clinical benefit of aCRT. ${ }^{3,4,6-9}$

Adaptive CRT can exert its physiologic effects via two mechanisms: one involving the effect of the fusion of LV pacing with intrinsic RV activation on electrical dyssynchrony, and the other via adaptive AV optimization. Moreover, there is a complex interaction between interventricular dyssynchrony and AV optimization. ${ }^{31,32}$ Our RCT showed that aCRT reduced RV uncoupling by significantly changing VEU, thereby reducing interventricular dyssynchrony, a known critical predictor of CRT response. ${ }^{33,34}$ In the previous studies, VEU was strongly associated with clinical outcomes. ${ }^{26}$ The magnitude of change in VEU has been shown to be the primary driver of acute hemodynamic CRT response. ${ }^{35}$

Our results support previous experimental and clinical studies ${ }^{10-13}$ indicating similar effects of LV and BiV pacing on LV intraventricular dyssynchrony. It should be noted that in our study, the protocol did not mandate the placement of the LV lead in the location corresponding to the latest activation. ${ }^{36,37}$ It is known that the degree of interventricular dyssynchrony depends on the location of LV and RV pacing, and the complex interaction of pacing sites with the 
medRxiv preprint doi: https://doi.org/10.1101/2020.09.14.20194415; this version posted September 15, 2020. The copyright holder for this

heterogeneous substrate in CRT recipients. ${ }^{38}$ Nevertheless, the aCRT-ELSYNC RCT results suggest that both reduction of RV uncoupling and adaptive AV optimization are responsible for the previously reported advantages of aCRT over conventional CRT: higher likelihood of CRT response, ${ }^{5}$ and reduction of AF occurrence. ${ }^{6-9}$ Our results are consistent with previous observations concluding that an optimal AV delay is necessary for effective fusion of LV pacing with intrinsic excitation and the most advantageous reduction of interventricular dyssynchrony. ${ }^{38}$

In our study population, only a few participants met strict LBBB criteria, and nearly half of the participants had an $\mathrm{S}$ wave in $\mathrm{V}_{5}-\mathrm{V}_{6}$, which explains why we observed both RV- and LVuncoupling. ${ }^{26}$ The presence of an $\mathrm{S}$ wave in $\mathrm{V}_{5}-\mathrm{V}_{6}$ has previously been associated with poor CRT response, HF re-hospitalizations and all-cause mortality. ${ }^{39}$ Bi-ventricular and RV enlargement ${ }^{40}$ and apical location of the LV posterior fascicular branch ${ }^{41}$ were suggested as possible mechanisms behind atypical $\mathrm{LBBB}$ with $\mathrm{S}$ wave in $\mathrm{V}_{5}-\mathrm{V}_{6}$. Our observation that conduction block in such atypical LBBB occurred in the anterior RV, as opposed to the interventricular groove in those who met the strict LBBB criteria, suggests yet another possible mechanism. Longitudinal dissociation of the His bundle and predestined conduction cables ${ }^{42}$ suggest that proximal conduction block of fibers that form downstream branches of both right and left bundles may produce atypical $\mathrm{LBBB}$ with $\mathrm{S}$ wave in $\mathrm{V}_{5}-\mathrm{V}_{6}$. We speculate that patients with this type of conduction abnormality should respond to His bundle pacing. This hypothesis should be tested in future prospective studies.

Similar to previous studies, ${ }^{26,43}$ we observed considerable heterogeneity in epicardial activation sequences. As observed in previous studies, ${ }^{35,44,45} \mathrm{RV}$ pacing and BiV pacing prolongs RVAT and increases RV uncoupling. In contrast, single-site LV pacing with fusion reduces RV uncoupling and interventricular dyssynchrony in a wide range of LBBB 
medRxiv preprint doi: https://doi.org/10.1101/2020.09.14.20194415; this version posted September 15, 2020. The copyright holder for this

morphologies, including IVCD and atypical $\mathrm{LBBB}$ with $\mathrm{S}$ wave in $\mathrm{V}_{5}-\mathrm{V}_{6}$, as demonstrated in this RCT.

The aCRT-ELSYNC RCT results did not find a significant correlation between metrics of electrical dyssynchrony measured on a surface ECG and the epicardial surface; however, both sets of metrics showed a significant reduction in the degree of dyssynchrony six months postCRT. This finding highlights the differences between the two approaches and their complementary value. The ECGI method ${ }^{20}$ utilized in this study is built on a pericardial potential source model, showing the distribution of electrical potentials on the pericardial surface of the heart. In contrast, surface ECG metrics of electrical dyssynchrony (QRS duration, QRS area ${ }^{27}$, and SAIQRST ${ }^{14,15,25}$ ) are global metrics of electrical dyssynchrony, a sum of dyssynchrony through endo-, mid-, epicardium, and both ventricles. ${ }^{46,47}$ Through results from the epicardial activation maps metrics, we could appreciate the variation in LV activation patterns at baseline and the reduction in VEU in only the aCRT group. From the surface ECG, the QRS area and SAIQRST significantly decreased post-CRT in both groups. Using both metrics allows for a comprehensive evaluation of electrical dyssynchrony, with both showing an overall reduction in electrical dyssynchrony post-CRT.

A weak correlation between ECGI measures of electrical dyssynchrony and QRS duration has been previously reported. ${ }^{26,38,48}$ Similarly to many previous ECGI studies, ${ }^{26,30,35,43-45,48}$ we observed highly variable patterns of epicardial activation and response to LV and BiV pacing, highlighting the importance of individualized planning of both $\mathrm{RV}^{49}$ and LV lead placement and assessment of the pacing effect. Studies using an ECG belt showed that electrical dyssynchrony measured on the body surface could provide a good prediction of hemodynamic CRT response $\mathrm{e}^{50}$ and LV remodeling, ${ }^{51}$ helping to optimize LV lead location. Simple VCG metrics (SAIQRST 
and QRS area) showed an advantage over QRS duration for the prediction of CRT response. ${ }^{14,15 \text {, }}$

${ }^{27}$ Experimental studies showed limitations of ECGI-derived dyssynchrony indices, which had only a moderate agreement with directly measured interventricular dyssynchrony. ${ }^{52}$ Available resources might dictate the choice regarding method of assessment of electrical dyssynchrony (VCG, ECG belt, ECGI) in clinical practice. Further development of these methods of assessment of electrical dyssynchrony is essential to equip physicians in a wide range of practice settings.

\section{Limitations}

The number of enrolled and randomized participants was modest. However, this is the first and largest RCT to date that studied detailed, noninvasively reconstructed epicardial mapping of electrical activation abnormalities in patients undergoing CRT. Leads placement was not standardized or guided by the study protocol; this requires further study. As we reconstructed activation on the epicardial surface only, the lack of information about septal and midmyocardial activation limited assessment of the dyssynchrony by ECGI.

\section{Acknowledgments:}

The authors thank the study participants and staff. We thank William Woodward, ARMRIT, for the help with the CMR data acquisition.

\section{Funding Sources:}

The study was funded by Medtronic, Inc, as a physician-initiated study (LGT). This work was partially supported by HL118277 (LGT). Oregon Clinical and Translational Research Institute grant (UL1TR002369) supported the RedCap. 
medRxiv preprint doi: https://doi.org/10.1101/2020.09.14.20194415; this version posted September 15, 2020. The copyright holder for this preprint (which was not certified by peer review) is the author/funder, who has granted medRxiv a license to display the preprint in perpetuity. All rights reserved. No reuse allowed without permission.

\section{Disclosures}

The study was funded by Medtronic, Inc, as a physician-initiated study (LGT). 
medRxiv preprint doi: https://doi.org/10.1101/2020.09.14.20194415; this version posted September 15, 2020. The copyright holder for this

\section{References}

1. Krum H, Lemke B, Birnie D, Lee KL, Aonuma K, Starling RC, Gasparini M, Gorcsan J, Rogers T, Sambelashvili A, Kalmes A and Martin D. A novel algorithm for individualized cardiac resynchronization therapy: rationale and design of the adaptive cardiac resynchronization therapy trial. Am Heart J. 2012;163:747-752 e1.

2. Martin DO, Lemke B, Birnie D, Krum H, Lee KL, Aonuma K, Gasparini M, Starling RC, Milasinovic G, Rogers T, Sambelashvili A, Gorcsan J, 3rd, Houmsse M and Adaptive CRTSI. Investigation of a novel algorithm for synchronized left-ventricular pacing and ambulatory optimization of cardiac resynchronization therapy: results of the adaptive CRT trial. Heart Rhythm. 2012;9:1807-14.

3. Birnie D, Lemke B, Aonuma K, Krum H, Lee KL, Gasparini M, Starling RC, Milasinovic G, Gorcsan J, 3rd, Houmsse M, Abeyratne A, Sambelashvili A and Martin DO. Clinical outcomes with synchronized left ventricular pacing: analysis of the adaptive CRT trial. Heart Rhythm. 2013;10:1368-74.

4. Starling RC, Krum H, Bril S, Tsintzos SI, Rogers T, Hudnall JH and Martin DO. Impact of a Novel Adaptive Optimization Algorithm on 30-Day Readmissions: Evidence From the Adaptive CRT Trial. JACC Heart failure. 2015;3:565-572.

5. Singh JP, Abraham WT, Chung ES, Rogers T, Sambelashvili A, Coles JA, Jr and Martin DO. Clinical response with adaptive CRT algorithm compared with CRT with echocardiography-optimized atrioventricular delay: a retrospective analysis of multicentre trials. EP Europace. 2013;15:1622-1628.

6. Singh JP, Cha Y-M, Lunati M, Chung ES, Li S, Smeets P and O'Donnell D. Real-world behavior of CRT pacing using the AdaptivCRT algorithm on patient outcomes: Effect on 
medRxiv preprint doi: https://doi.org/10.1101/2020.09.14.20194415; this version posted September 15, 2020. The copyright holder for this

mortality and atrial fibrillation incidence. Journal of Cardiovascular Electrophysiology. 2020;31:825-833.

7. Gasparini M, Birnie D, Lemke B, Aonuma K, Lee KL, Gorcsan J, 3rd, Landolina M, Klepfer R, Meloni S, Cicconelli M, Grammatico A and Martin DO. Adaptive Cardiac Resynchronization Therapy Reduces Atrial Fibrillation Incidence in Heart Failure Patients With Prolonged AV Conduction: The Adaptive CRT Randomized Trial. Circ Arrhythm Electrophysiol. 2019;12:e007260.

8. Hsu JC, Birnie D, Stadler RW, Cerkvenik J, Feld GK and Birgersdotter-Green U. Adaptive cardiac resynchronization therapy is associated with decreased risk of incident atrial fibrillation compared to standard biventricular pacing: A real-world analysis of 37,450 patients followed by remote monitoring. Heart Rhythm. 2019;16:983-989.

9. Birnie D, Hudnall H, Lemke B, Aonuma K, Lee KL, Gasparini M, Gorcsan J, 3rd, Cerkvenik J and Martin DO. Continuous optimization of cardiac resynchronization therapy reduces atrial fibrillation in heart failure patients: Results of the Adaptive Cardiac Resynchronization Therapy Trial. Heart Rhythm. 2017;14:1820-1825.

10. Leclercq C, Faris O, Tunin R, Johnson J, Kato R, Evans F, Spinelli J, Halperin H, McVeigh E and Kass DA. Systolic Improvement and Mechanical Resynchronization Does Not Require Electrical Synchrony in the Dilated Failing Heart With Left Bundle-Branch Block. Circulation. 2002;106:1760-1763.

11. Thibault B, Ducharme A, Harel F, White M, O'Meara E, Guertin MC, Lavoie J, FrasureSmith N, Dubuc M, Guerra P, Macle L, Rivard L, Roy D, Talajic M, Khairy P and Evaluation of Resynchronization Therapy for Heart Failure I. Left ventricular versus simultaneous 
medRxiv preprint doi: https://doi.org/10.1101/2020.09.14.20194415; this version posted September 15, 2020. The copyright holder for this

biventricular pacing in patients with heart failure and a QRS complex $>/=120$ milliseconds.

Circulation. 2011;124:2874-81.

12. Boriani G, Kranig W, Donal E, Calo L, Casella M, Delarche N, Lozano IF, Ansalone G, Biffi M, Boulogne E, Leclercq C and group BLHs. A randomized double-blind comparison of biventricular versus left ventricular stimulation for cardiac resynchronization therapy: the Biventricular versus Left Univentricular Pacing with ICD Back-up in Heart Failure Patients (BLEFT HF) trial. Am Heart J. 2010;159:1052-1058 e1.

13. Rao RK, Kumar UN, Schafer J, Viloria E, De Lurgio D and Foster E. Reduced ventricular volumes and improved systolic function with cardiac resynchronization therapy: a randomized trial comparing simultaneous biventricular pacing, sequential biventricular pacing, and left ventricular pacing. Circulation. 2007;115:2136-44.

14. Tereshchenko LG, Cheng A, Park J, Wold N, Meyer TE, Gold MR, Mittal S, Singh J, Stein KM, Ellenbogen KA and SMART-AV Trial Investigators. Novel measure of electrical dyssynchrony predicts response in cardiac resynchronization therapy: Results from the SMARTAV Trial. Heart Rhythm. 2015;12:2402-10.

15. Jacobsson J, Borgquist R, Reitan C, Ghafoori E, Chatterjee NA, Kabir M, Platonov PG, Carlson J, Singh JP and Tereshchenko LG. Usefulness of the Sum Absolute QRST Integral to Predict Outcomes in Patients Receiving Cardiac Resynchronization Therapy. Am J Cardiol. 2016;118:389-95.

16. Harris PA, Taylor R, Thielke R, Payne J, Gonzalez N and Conde JG. Research electronic data capture (REDCap) — A metadata-driven methodology and workflow process for providing translational research informatics support. Journal of Biomedical Informatics. 2009;42:377-381. 
medRxiv preprint doi: https://doi.org/10.1101/2020.09.14.20194415; this version posted September 15, 2020. The copyright holder for this

17. Harris PA, Taylor R, Minor BL, Elliott V, Fernandez M, O'Neal L, McLeod L, Delacqua G, Delacqua F, Kirby J and Duda SN. The REDCap consortium: Building an international community of software platform partners. Journal of Biomedical Informatics. 2019;95:103208.

18. Epstein AE, DiMarco JP, Ellenbogen KA, Estes NA, 3rd, Freedman RA, Gettes LS, Gillinov AM, Gregoratos G, Hammill SC, Hayes DL, Hlatky MA, Newby LK, Page RL, Schoenfeld MH, Silka MJ, Stevenson LW, Sweeney MO, Tracy CM, Epstein AE, Darbar D, DiMarco JP, Dunbar SB, Estes NA, 3rd, Ferguson TB, Jr., Hammill SC, Karasik PE, Link MS, Marine JE, Schoenfeld MH, Shanker AJ, Silka MJ, Stevenson LW, Stevenson WG, Varosy PD, American College of Cardiology F, American Heart Association Task Force on Practice G and Heart Rhythm S. 2012 ACCF/AHA/HRS focused update incorporated into the ACCF/AHA/HRS 2008 guidelines for device-based therapy of cardiac rhythm abnormalities: a report of the American College of Cardiology Foundation/American Heart Association Task Force on Practice Guidelines and the Heart Rhythm Society. J Am Coll Cardiol. 2013;61:e6-75.

19. Horacek BM and Clements JC. The inverse problem of electrocardiography: a solution in terms of single- and double-layer sources of the epicardial surface. Math Biosci. 1997;144:119-

\section{4.}

20. Ramanathan C, Ghanem RN, Jia P, Ryu K and Rudy Y. Noninvasive electrocardiographic imaging for cardiac electrophysiology and arrhythmia. NatMed. 2004;10:422-428.

21. Perez-Alday EA, Haq KT, German DM, Hamilton C, Johnson K, Phan F, Rogovoy NM, Yang K, Wirth A, Thomas JA, Dalouk K, Fuss C, Ferencik M, Heitner S and Tereshchenko LG. Mechanisms of Arrhythmogenicity in Hypertrophic Cardiomyopathy: Insight From Non-invasive Electrocardiographic Imaging. Front Physiol. 2020;11:344. 
medRxiv preprint doi: https://doi.org/10.1101/2020.09.14.20194415; this version posted September 15, 2020. The copyright holder for this

22. Coll-Font J, Burton BM, Tate JD, Erem B, Swenson DJ, Wang D, Brooks DH, van Dam $\mathrm{P}$ and Macleod RS. New Additions to the Toolkit for Forward/Inverse Problems in Electrocardiography within the SCIRun Problem Solving Environment. Computing in cardiology. 2014;2014:213-216.

23. Perez-Alday EA, Thomas JA, Kabir M, Sedaghat G, Rogovoy N, van Dam E, van Dam P, Woodward W, Fuss C, Ferencik M and Tereshchenko LG. Torso geometry reconstruction and body surface electrode localization using three-dimensional photography. J Electrocardiol. 2018;51:60-67.

24. Yushkevich PA, Piven J, Hazlett HC, Smith RG, Ho S, Gee JC and Gerig G. User-guided 3D active contour segmentation of anatomical structures: significantly improved efficiency and reliability. NeuroImage. 2006;31:1116-28.

25. Tereshchenko LG, Ghafoori E, Kabir MM and Kowalsky M. Electrical Dyssynchrony on Noninvasive Electrocardiographic Mapping correlates with SAI QRST on surface ECG.

Computing in cardiology. 2015;42:69-72.

26. Ploux S, Lumens J, Whinnett Z, Montaudon M, Strom M, Ramanathan C, Derval N, Zemmoura A, Denis A, De Guillebon M, Shah A, Hocini M, Jaïs P, Ritter P, Haïssaguerre M, Wilkoff BL and Bordachar P. Noninvasive Electrocardiographic Mapping to Improve Patient Selection for Cardiac Resynchronization Therapy: Beyond QRS Duration and Left Bundle Branch Block Morphology. Journal of the American College of Cardiology. 2013;61:2435-2443.

27. van Stipdonk AMW, Ter Horst I, Kloosterman M, Engels EB, Rienstra M, Crijns H, Vos MA, van Gelder IC, Prinzen FW, Meine M, Maass AH and Vernooy K. QRS Area Is a Strong Determinant of Outcome in Cardiac Resynchronization Therapy. Circ Arrhythm Electrophysiol. 2018;11:e006497. 
medRxiv preprint doi: https://doi.org/10.1101/2020.09.14.20194415; this version posted September 15, 2020. The copyright holder for this

28. Perez-Alday EA, Li-Pershing Y, Bender A, Hamilton C, Thomas JA, Johnson K, Lee TL, Gonzales R, Li A, Newton K and Tereshchenko LG. Importance of the heart vector origin point definition for an ECG analysis: The Atherosclerosis Risk in Communities (ARIC) study. Comput Biol Med. 2019;104:127-138.

29. Perez-Alday EA, Bender A, German D, Mukundan SV, Hamilton C, Thomas JA, LiPershing Y and Tereshchenko LG. Dynamic predictive accuracy of electrocardiographic biomarkers of sudden cardiac death within a survival framework: the Atherosclerosis Risk in Communities (ARIC) study. BMC cardiovascular disorders. 2019;19:255.

30. Ghosh S, Silva JN, Canham RM, Bowman TM, Zhang J, Rhee EK, Woodard PK and Rudy Y. Electrophysiologic substrate and intraventricular left ventricular dyssynchrony in nonischemic heart failure patients undergoing cardiac resynchronization therapy. Heart Rhythm. 2011;8:692-9.

31. Gold MR, Yu Y, Singh JP, Birgersdotter-Green U, Stein KM, Wold N, Meyer TE and Ellenbogen KA. Effect of Interventricular Electrical Delay on Atrioventricular Optimization for Cardiac Resynchronization Therapy. Circ Arrhythm Electrophysiol. 2018;11:e06055.

32. Strocchi M, Lee AWC, Neic A, Bouyssier J, Gillette K, Plank G, Elliott MK, Gould J, Behar JM, Sidhu B, Mehta V, Bishop MJ, Vigmond EJ, Rinaldi CA and Niederer SA. Hisbundle and left bundle pacing with optimized atrioventricular delay achieve superior electrical synchrony over endocardial and epicardial pacing in left bundle branch block patients. Heart Rhythm. 2020.

33. Waks JW, Perez-Alday EA and Tereshchenko LG. Understanding Mechanisms of Cardiac Resynchronization Therapy Response to Improve Patient Selection and Outcomes. Circ Arrhythm Electrophysiol. 2018;11:e006290. 
medRxiv preprint doi: https://doi.org/10.1101/2020.09.14.20194415; this version posted September 15, 2020. The copyright holder for this

34. Huntjens PR PS, Strik M, Walmsley J, Ritter P, Haissaguerre M, Prinzen FW, Delhaas T, Lumens J, Bordachar P. Electrical Substrates Driving Response to Cardiac Resynchronization Therapy: A Combined Clinical - Computational Evaluation. Circ Arrhythm Electrophysiol. 2018;11:e005647.

35. Ploux S, Eschalier R, Whinnett ZI, Lumens J, Derval N, Sacher F, Hocini M, Jais P, Dubois R, Ritter P, Haissaguerre M, Wilkoff BL, Francis DP and Bordachar P. Electrical dyssynchrony induced by biventricular pacing: implications for patient selection and therapy improvement. Heart Rhythm. 2015;12:782-91.

36. Behar JM, Rajani R, Pourmorteza A, Preston R, Razeghi O, Niederer S, Adhya S, Claridge S, Jackson T, Sieniewicz B, Gould J, Carr-White G, Razavi R, McVeigh E and Rinaldi CA. Comprehensive use of cardiac computed tomography to guide left ventricular lead placement in cardiac resynchronization therapy. Heart Rhythm. 2017;14:1364-1372.

37. Khan FZ, Virdee MS, Palmer CR, Pugh PJ, O'Halloran D, Elsik M, Read PA, Begley D, Fynn SP and Dutka DP. Targeted Left Ventricular Lead Placement to Guide Cardiac Resynchronization Therapy: The TARGET Study: A Randomized, Controlled Trial. Journal of the American College of Cardiology. 2012;59:1509-1518.

38. Jia P, Ramanathan C, Ghanem RN, Ryu K, Varma N and Rudy Y. Electrocardiographic imaging of cardiac resynchronization therapy in heart failure: observation of variable electrophysiologic responses. Heart Rhythm. 2006;3:296-310.

39. Jiang Z, Qiu Y, Qian Z, Wang Y, Zhao Y, Hou X, Liang Y, Zheng L, Xu G, Su Y, Gu X and Zou J. An S wave in ECG lead V6 predicts poor response to cardiac resynchronization therapy and long-term outcome. Heart Rhythm. 2020;17:265-272. 
medRxiv preprint doi: https://doi.org/10.1101/2020.09.14.20194415; this version posted September 15, 2020. The copyright holder for this

40. Leonelli FM, Bagliani G, De Ponti R and Padeletti L. Intraventricular Delay and Blocks. Cardiac Electrophysiology Clinics. 2018;10:211-231.

41. Cardone-Noott L, Bueno-Orovio A, Mincholé A, Zemzemi N and Rodriguez B. Human ventricular activation sequence and the simulation of the electrocardiographic QRS complex and its variability in healthy and intraventricular block conditions. EP Europace. 2016;18:iv4-iv15.

42. Sharma PS, Vijayaraman P and Ellenbogen KA. Permanent His bundle pacing: shaping the future of physiological ventricular pacing. Nat Rev Cardiol. 2019.

43. Varma N, Jia P and Rudy Y. Electrocardiographic imaging of patients with heart failure with left bundle branch block and response to cardiac resynchronization therapy. $J$ Electrocardiol. 2007;40:S174-S178.

44. Varma N, Jia P, Ramanathan C and Rudy Y. RV electrical activation in heart failure during right, left, and biventricular pacing. JACC Cardiovasc Imaging. 2010;3:567-75.

45. Eschalier R, Ploux S, Lumens J, Whinnett Z, Varma N, Meillet V, Ritter P, Jaïs P, Haïssaguerre $\mathrm{M}$ and Bordachar P. Detailed analysis of ventricular activation sequences during right ventricular apical pacing and left bundle branch block and the potential implications for cardiac resynchronization therapy. Heart Rhythm. 2015;12:137-143.

46. Tereshchenko LG, Henrikson CA and Berger RD. Strong coherence between heart rate variability and intracardiac repolarization lability during biventricular pacing is associated with reverse electrical remodeling of the native conduction and improved outcome. J Electrocardiol. 2011;44:713-7.

47. Tereshchenko LG, Henrikson CA, Stempniewicz P, Han L and Berger RD. Antiarrhythmic effect of reverse electrical remodeling associated with cardiac resynchronization therapy. Pacing Clin Electrophysiol. 2011;34:357-64. 
medRxiv preprint doi: https://doi.org/10.1101/2020.09.14.20194415; this version posted September 15, 2020. The copyright holder for this

48. Silva JN, Ghosh S, Bowman TM, Rhee EK, Woodard PK and Rudy Y. Cardiac resynchronization therapy in pediatric congenital heart disease: insights from noninvasive electrocardiographic imaging. Heart Rhythm. 2009;6:1178-1185.

49. Jackson T, Claridge S, Behar J, Sieniewicz B, Gould J, Porter B, Sidhu B, Yao C, Lee A, Niederer S and Rinaldi CA. Differential effect with septal and apical RV pacing on ventricular activation in patients with left bundle branch block assessed by non-invasive electrical imaging and in silico modelling. J Interv Card Electrophysiol. 2020;57:115-123.

50. Johnson WB, Vatterott PJ, Peterson MA, Bagwe S, Underwood RD, Bank AJ, Gage RM, Ramza B, Foreman BW, Splett V, Haddad T, Gillberg JM and Ghosh S. Body surface mapping using an ECG belt to characterize electrical heterogeneity for different left ventricular pacing sites during cardiac resynchronization: Relationship with acute hemodynamic improvement. Heart Rhythm. 2017;14:385-391.

51. Gage RM, Curtin AE, Burns KV, Ghosh S, Gillberg JM and Bank AJ. Changes in electrical dyssynchrony by body surface mapping predict left ventricular remodeling in patients with cardiac resynchronization therapy. Heart Rhythm. 2017;14:392-399.

52. Bear LR, Huntjens PR, Walton RD, Bernus O, Coronel R and Dubois R. Cardiac electrical dyssynchrony is accurately detected by noninvasive electrocardiographic imaging. Heart Rhythm. 2018;15:1058-1069. 
medRxiv preprint doi: https://doi.org/10.1101/2020.09.14.20194415; this version posted September 15, 2020. The copyright holder for this preprint (which was not certified by peer review) is the author/funder, who has granted medRxiv a license to display the preprint in perpetuity.

Table 1: Baseline clinical and demographic characteristics of the study participants

\begin{tabular}{|c|c|c|c|c|}
\hline Characteristic & All $(n=32)$ & $\begin{array}{l}\text { Conventional } \\
\text { CRT }(n=15)\end{array}$ & $\begin{array}{l}\text { Adaptive } \\
\text { CRT (n=12) }\end{array}$ & $\begin{array}{l}\text { Registry } \\
(n=5)\end{array}$ \\
\hline Age(SD), y & $64.4(11.5)$ & $65.3(12.2)$ & $62.2(10.3)$ & $67.3(13.6)$ \\
\hline Female, $n(\%)$ & $11(34.4)$ & $5(33.3)$ & $4(33.3)$ & $2(40.0)$ \\
\hline White, $\mathrm{n}(\%)$ & $31(96.9)$ & $15(100)$ & 11(91.7) & $5(100.0)$ \\
\hline Body mass index(SD), $\mathrm{kg} / \mathrm{m}^{2}$ & $31.3(7.4)$ & $30.2(4.3)$ & $33.1(9.1)$ & $30.2(10.8)$ \\
\hline Ischemic cardiomyopathy, n(\%) & $17(53.1)$ & $9(60.0)$ & $5(41.7)$ & $3(60.0)$ \\
\hline Myocardial infarction history, $\mathrm{n}(\%)$ & $9(28.1)$ & $4(26.7)$ & $3(25.0)$ & $2(40.0)$ \\
\hline Revascularization history, $\mathrm{n}(\%)$ & $15(46.9)$ & $8(53.3)$ & $5(41.7)$ & $2(40.0$ \\
\hline 3 -vessel disease, $n(\%)$ & $8(25.0)$ & $4(26.7)$ & $3(25.0)$ & $1(20.0)$ \\
\hline NYHA class II, n(\%) & $21(65.6)$ & $9(60.0)$ & $8(66.7)$ & $4(80.0)$ \\
\hline NYHA class III, n(\%) & $11(34.4)$ & $6(40.0)$ & $4(33.3)$ & $1(20.0)$ \\
\hline QRS duration(SD), ms & $155.1(20.9)$ & $151.3(24.3)$ & $160.6(19.0)$ & $153.1(20.9)$ \\
\hline QTc interval(SD), ms & $492.5(40.6)$ & $492.0(45.0)$ & $496.1(35.1)$ & $485.6(47.2)$ \\
\hline PR interval(SD), ms & $181.2(22.9)$ & $187.6(21.6)$ & $176.6(21.0)$ & $170.0(35.4)$ \\
\hline Strict LBBB, $\mathrm{n}(\%)$ & $4(12.5)$ & $1(6.7)$ & $3(25.0)$ & 0 \\
\hline IVCD, $\mathrm{n}(\%)$ & $28(87.5)$ & $14(93.3)$ & $1(75.0)$ & $5(100.0)$ \\
\hline Upgrade from ICD, n(\%) & $1(3.1)$ & 0 & $1(8.3)$ & 0 \\
\hline Atrial fibrillation history, $\mathrm{n}(\%)$ & $7(21.9)$ & $3(20.0)$ & $2(16.7)$ & $2(40.0)$ \\
\hline Diabetes, $n(\%)$ & $7(21.9)$ & $4(26.7)$ & $2(16.7)$ & $2(20.0$ \\
\hline Hypertension, n(\%) & $24(75.0)$ & $11(73.3)$ & $8(66.7)$ & $5(100.0)$ \\
\hline COPD, $n(\%)$ & $4(12.5)$ & $3(20.0)$ & $1(8.3)$ & 0 \\
\hline Never-smoker, n(\%) & $20(62.5)$ & $7(46.7)$ & $8(66.7)$ & $5(100.0)$ \\
\hline Beta-blockers, n(\%) & $31(96.9)$ & $14(93.3)$ & $12(100.0)$ & $5(100.0)$ \\
\hline $\mathrm{ACEI}$ or $\mathrm{ARB}, \mathrm{n}(\%)$ & $28(87.5)$ & 13(86.7) & $10(83.3)$ & $5(100.0)$ \\
\hline LVEF(SD), \% & $28.4(8.0)$ & $26.0(8.6)$ & $29.7(7.5)$ & $32.3(6.4)$ \\
\hline $\operatorname{LVDDi}(\mathrm{SD}), \mathrm{cm} / \mathrm{m}^{2}$ & $3.2(0.5)$ & $3.3(0.6)$ & $3.1(0.4)$ & $3.1(0.3)$ \\
\hline $\operatorname{LVSDi}(\mathrm{SD}), \mathrm{cm} / \mathrm{m}^{2}$ & $2.7(0.5)$ & $3.0(0.5)$ & $2.7(0.4)$ & $2.6(0.2)$ \\
\hline
\end{tabular}

$\mathrm{SD}=$ standard deviation; NYHA=New York Heart Association; $\mathrm{ICD}=$ implantable cardioverterdefibrillator; $\mathrm{LBBB}=$ lect fundle branch block; IVCD=interventricular conduction delay; $\mathrm{COPD}=$ chronic obstructive pulmonary disease; $\mathrm{ACEI}=$ angiotensin-converting enzyme inhibitor; $\mathrm{ARB}=$ angiotensin receptor blocker; $\mathrm{LVEF}=$ left ventricular ejection fraction; $\mathrm{LVDDi}=$ left ventricular diastolic dimension indexed to body surface area; LVSDi=left ventricular systolic dimension indexed to body surface area. 
Table 2: Comparison of ventricular epicardial activation metrics of electrical dyssynchrony

\begin{tabular}{|c|c|c|c|c|c|}
\hline & Conventional CRT $(\mathrm{n}=15)$ & $P_{\text {pre-post }}$ & Adaptive CRT (n=12) & $P_{\text {pre-post }}$ & $P$-value \\
\hline Baseline TAT median(IQR),ms & $192(154-213)$ & - & 190(172-215) & - & 0.801 \\
\hline Post-CRT TAT median(IQR),ms & 111(94-126) & - & 101(98-134) & - & 0.674 \\
\hline Difference TAT median(IQR),ms & $-69(-54$ to -124$)$ & 0.0002 & $-78(-54$ to -111$)$ & 0.0005 & 0.857 \\
\hline Baseline LVAT median(IQR),ms & $172(138-213)$ & - & 187(172-213) & - & 0.622 \\
\hline Baseline mean RV time median(IQR), ms & $169(127-198)$ & & $158(142-184)$ & & 0.829 \\
\hline Post-CRT mean RV time median(IQR), ms & $105(91-133)$ & & $107(100-148)$ & & 0.347 \\
\hline Difference mean RV time median(IQR), ms & $-48(0107$ to -3$)$ & 0.003 & $-47(-59$ to -23$)$ & 0.002 & 0.614 \\
\hline Baseline mean LV time median(IQR), ms & $160(136-214)$ & & 132(121-151) & & 0.083 \\
\hline Post-CRT mean LV time median(IQR), ms & $106(79-141)$ & & 108(93-132) & & 0.905 \\
\hline Difference mean LV time median(IQR), ms & $-50(-83$ to -14$)$ & 0.003 & $-27(-36$ to -8$)$ & 0.043 & 0.183 \\
\hline Baseline LVAT median(IQR),ms & $172(138-213)$ & - & 187(172-213) & - & 0.622 \\
\hline Post-CRT LVAT median(IQR),ms & $104(87-126)$ & - & $100(93-131)$ & - & 0.895 \\
\hline Difference LVAT median(IQR),ms & $-58(-36$ to -124$)$ & 0.0004 & $-75(-48$ to -110$)$ & 0.0005 & 0.782 \\
\hline Baseline RVAT median(IQR),ms & $187(141-211)$ & - & $185(153-202)$ & - & 0.895 \\
\hline Post-CRT RVAT median(IQR),ms & $110(87-126)$ & - & $102(89-125)$ & - & 0.783 \\
\hline Difference RVAT median(IQR),ms & $-60(-22$ to -111$)$ & 0.0006 & $-83(-60$ to -91$)$ & 0.0005 & 0.406 \\
\hline Baseline VEU median(IQR),ms & $+2.3(-34.8$ to 17.2$)$ & & $-28.4(-40.3$ to -11.2$)$ & & 0.183 \\
\hline Post-CRT VEU median(IQR),ms & $-3.3(-13.3$ to 18.0$)$ & & $-9.1(-18.2$ to 4.7$)$ & & 0.347 \\
\hline Difference VEU median(IQR),ms & $21.4(-30.0$ to 49.9$)$ & 0.525 & $18.9(4.3$ to 29.2$)$ & 0.034 & 0.719 \\
\hline Baseline EDI $I_{v}$ median(IQR), ms & $52.5(41.8-68.5)$ & - & $53.1(40.2-69.2)$ & - & 0.792 \\
\hline Post-CRT EDIV median(IQR), ms & $30.6(23.6-45.2)$ & - & $30.8(22.1-46.1)$ & - & 0.683 \\
\hline Difference EDIV median(IQR), ms & $-12.9(-6.6$ to -38.9$)$ & 0.0001 & $-16.4(-8.1$ to -40.1$)$ & 0.0005 & 0.755 \\
\hline Baseline $\mathrm{EDI}_{\mathrm{LV}}$ median(IQR), ms & $50.1(32.8-73.2)$ & - & $47.5(40.6-64.2)$ & - & 0.981 \\
\hline Post-CRT EDI $\mathrm{IV}_{\mathrm{LV}}$ median(IQR), ms & $31.6(23.5-42.0)$ & - & $31.1(25.1-44.0)$ & - & 0.943 \\
\hline Difference $\mathrm{EDI}_{\mathrm{LV}}$ median(IQR), ms & $-11.6(-0.2$ to -51.2$)$ & 0.0002 & $-13.1(05.6$ to -35.1$)$ & 0.0005 & 0.943 \\
\hline Baseline $\mathrm{EDI}_{\mathrm{RV}}$ median(IQR),ms & $37.0(35.5-67.7)$ & - & $44.4(28.8-59.4)$ & - & 0.867 \\
\hline Post-CRT EDI $I_{R V}$ median(IQR),ms & $29.2(21.9-41.1)$ & - & $22.6(17.3-39.0)$ & - & 0.347 \\
\hline Difference EDI $I_{R V}$ median(IQR),ms & $-17.7(+8.3$ to -37.8$)$ & 0.0001 & $-20.3(-9.3$ to -32.7$)$ & 0.0005 & 0.943 \\
\hline
\end{tabular}

$P_{\text {pre-post }}=P$-value for difference baseline - post-CRT 
Table 3: Comparison of surface ECG metrics of electrical dyssynchrony

\begin{tabular}{|c|c|c|c|c|c|}
\hline & Conventional CRT $(\mathrm{n}=15)$ & $P_{\text {pre-post }}$ & Adaptive CRT $(\mathrm{n}=12)$ & $P_{\text {pre-post }}$ & $P$-value \\
\hline Baseline QRS duration median(IQR), ms & $156(135-174)$ & - & $166(145-172)$ & - & 0.379 \\
\hline Post-CRT QRS duration median(IQR), ms & $139(124-158)$ & - & $136(120-149)$ & - & 0.783 \\
\hline Difference QRS duration median(IQR), ms & $-9(-31$ to 2$)$ & 0.076 & $-31.5(-38$ to -19$)$ & 0.043 & 0.128 \\
\hline Baseline SAIQRST median(IQR), mVms & $210(142-299)$ & - & $225(154-405)$ & - & 0.456 \\
\hline Post-CRT SAIQRST median(IQR), mVms & $126(106-189)$ & - & $143(103-182)$ & - & 0.943 \\
\hline Difference SAIQRST median(IQR), mVms & $-49(-108$ to -19$)$ & 0.005 & $-105(-254$ to -22$)$ & 0.012 & 0.427 \\
\hline Baseline VM QRS area median(IQR), mVms & $243(202-414)$ & - & $353(215-647)$ & - & 0.548 \\
\hline Post-CRT VM QRS area median(IQR), mVms & $190(152-257)$ & - & $156(137-263)$ & - & 0.546 \\
\hline Difference VM QRS area median(IQR), mVms & $-82(-250$ to 10$)$ & 0.030 & $-215(-458$ to 17$)$ & 0.021 & 0.323 \\
\hline
\end{tabular}

$P_{\text {pre-post }}=P$-value for difference baseline - post-CRT; VM=vector magnitude. 
Table 4: Quality of life and 6-minute walk distance changes

\begin{tabular}{llll}
\hline & Conventional CRT (n=15) & Adaptive CRT (n=12) & $P$-value \\
\hline Baseline 6-min walk distance median(IQR), $m$ & $360(312-374)$ & $362(345-438)$ & 0.358 \\
Post-CRT 6-min walk distance median(IQR), m & $352(318-412)$ & $368(328-402)$ & 0.820 \\
Difference 6-min walk distance median(IQR), m & $+18(-12$ to +41$)$ & $-19(-76$ to +57$)$ & 0.804 \\
Baseline MLHFQ total score median(IQR) & $56(20-70)$ & $33(15-65)$ & 0.373 \\
Post-CRT MLHFQ total score median(IQR) & $30(11-50)$ & $21(8-44)$ & 0.478 \\
Difference MLHFQ total score median(IQR) & $-20(-30$ to -4$)$ & $-7(-15$ to 0.5$)$ & 0.353 \\
Difference SF-36 physical functioning median(IQR) & $0(0$ to +25$)$ & $+10(-5$ to +18$)$ & 0.970 \\
Difference SF-36 role physical median(IQR) & $0(0$ to +25$)$ & $+13(0$ to +38$)$ & 0.409 \\
Difference SF-36 role emotional median(IQR) & $0(0$ to 0$)$ & $0(0$ to +50$)$ & 0.724 \\
Difference SF-36 energy/fatigue median(IQR) & $+10(+5$ to +35$)$ & $+8(-10$ to +18$)$ & 0.255 \\
Difference SF-36 emotional median(IQR) & $+4(-8$ to +16$)$ & $0(-6$ to +16$)$ & 0.929 \\
Difference SF-36 social functioning median(IQR) & $+13(0$ to +25$)$ & $0(0$ to +6$)$ & 0.396 \\
Difference SF-36 pain score median(IQR) & $+13(-10$ to +23$)$ & $0(-6$ to +11$)$ & 0.364 \\
Difference SF-36 general health median(IQR) & $+10(-5$ to +10$)$ & $-5(-8$ to 10$)$ & 0.474 \\
\hline
\end{tabular}


medRxiv preprint doi: https://doi.org/10.1101/2020.09.14.20194415; this version posted September 15, 2020. The copyright holder for this

\section{Figure legends}

Figure 1: Study workflow. (A) CT scan or CMR provided the geometry of the ventricles and the torso. Images underwent segmentation, structure identification, geometric modeling and meshing. The 3D meshes of the ventricles and torso were created. (B) Body surface potential (BSP) was recorded using the 128 electrodes. 3D photography was used to record the electrodes locations on a torso. The torso geometric models based on the $3 \mathrm{D}$ photography and CT/CMR were co-registered. (C) Epicardial EGM reconstruction using the SCIRun inverse solution module. Local activation for each epicardial node was obtained as the point of the steepest downward slope (minimum dV/dt) of the corresponding EGM. An epicardial activation map was generated.

Figure 2. Study flowchart.

Figure 3: Representative example of epicardial activation in a female participant with NICM and typical LBBB at baseline (A) and 6-month post-aCRT in the treatment arm (B) in (i) anterior, (ii) left lateral, and (iii) posterior views. A white dashed line marks the interventricular groove. Epicardial 10-ms isochrones show local activation time (LAT), measured from the surface ECG QRS onset to minimum $\mathrm{dV} / \mathrm{dt}$, color-coded from red (early) to blue (late). Thick black lines (crowded isochrones) indicate line/region of conduction block.

Figure 4: Representative example of epicardial activation in a female participant with NICM and IVCD (atypical LBBB with S in V5-V6) at baseline (A) and 6-month post-BiV CRT in the control arm (B) in (i) anterior, (ii) left lateral, and (iii) posterior views. See Figure 3 legend for details. 
medRxiv preprint doi: https://doi.org/10.1101/2020.09.14.20194415; this version posted September 15, 2020. The copyright holder for this preprint (which was not certified by peer review) is the author/funder, who has granted medRxiv a license to display the preprint in perpetuity. All rights reserved. No reuse allowed without permission.

Figure 5. Change in the ventricular electrical uncoupling (VEU) between two study visits (green line) in every randomized study participant (green dot), in (A) conventional CRT, and (B) adaptive CRT arms. 
Figure 1:

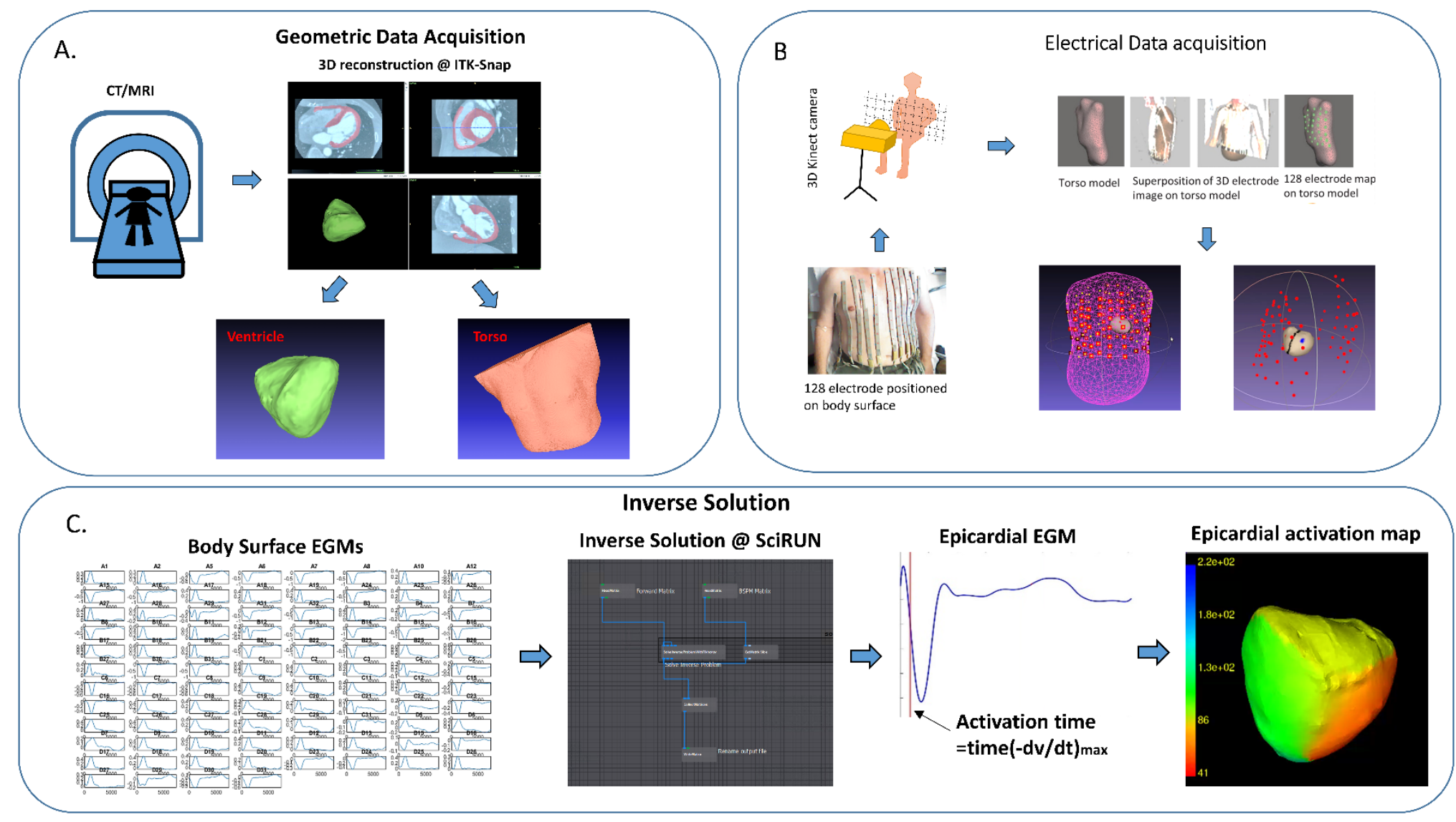


Figure 2:

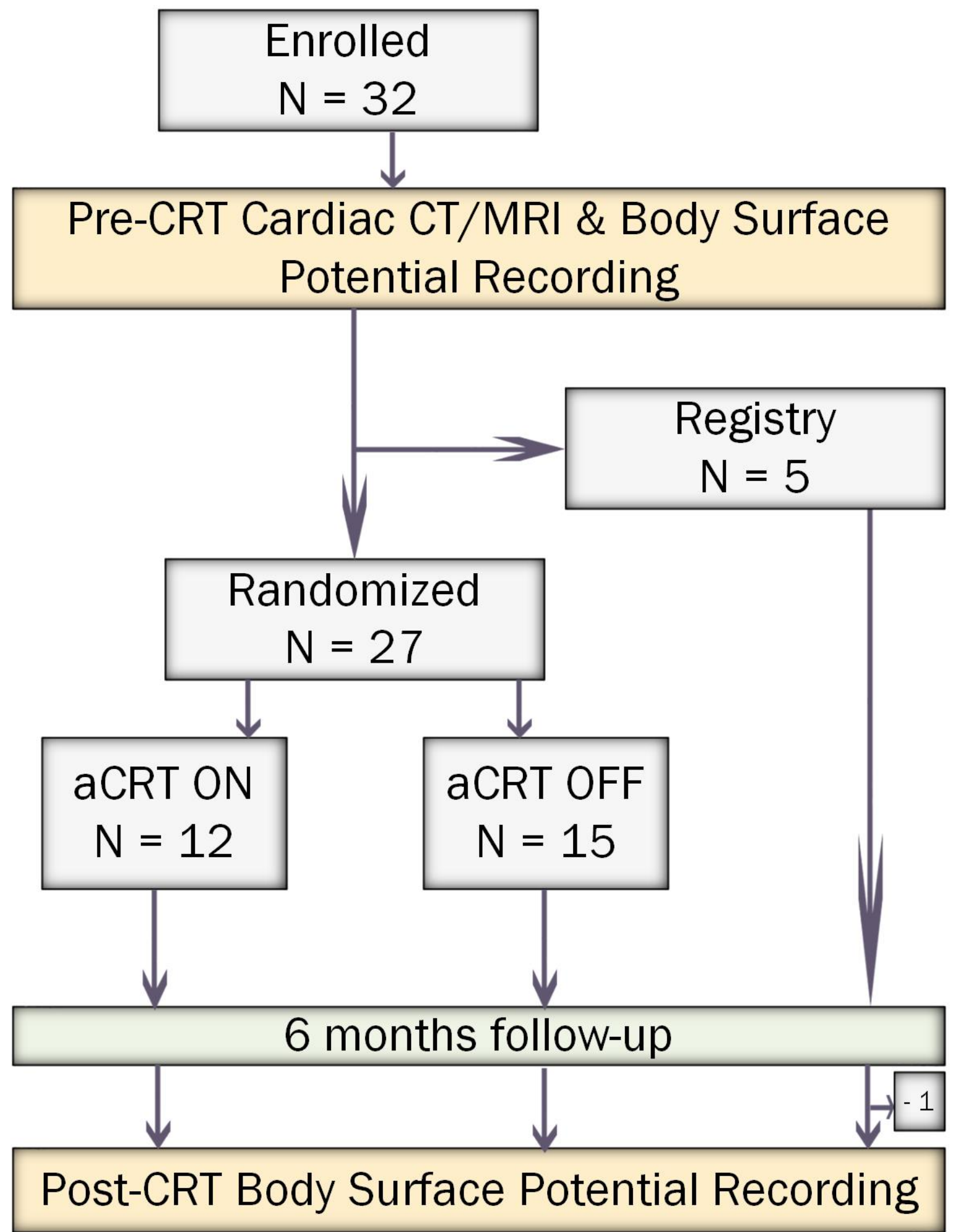


Figure 3:

\section{Anterior}

A.

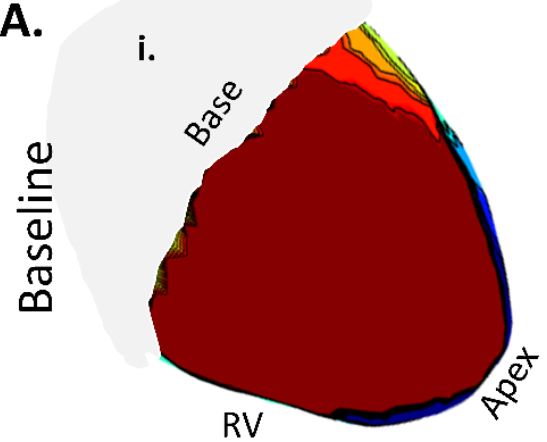

B.

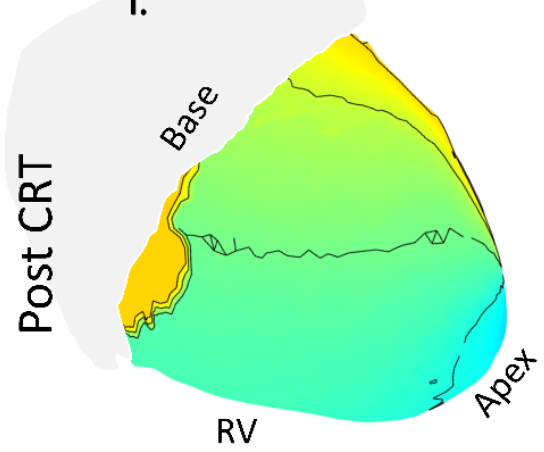

Left lateral

ii.

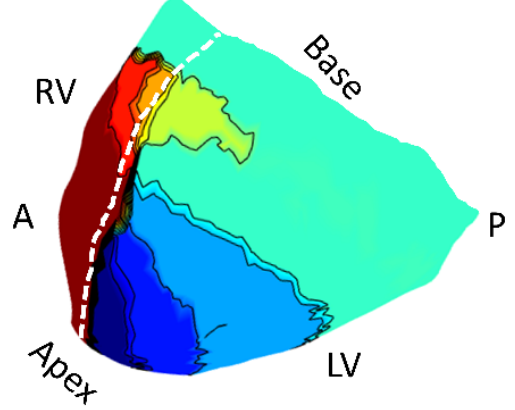

ii.

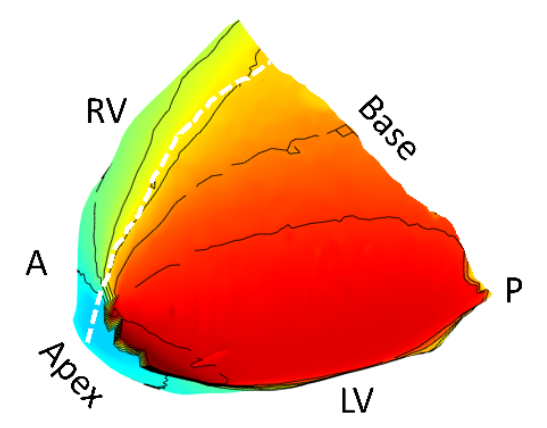

Posterior

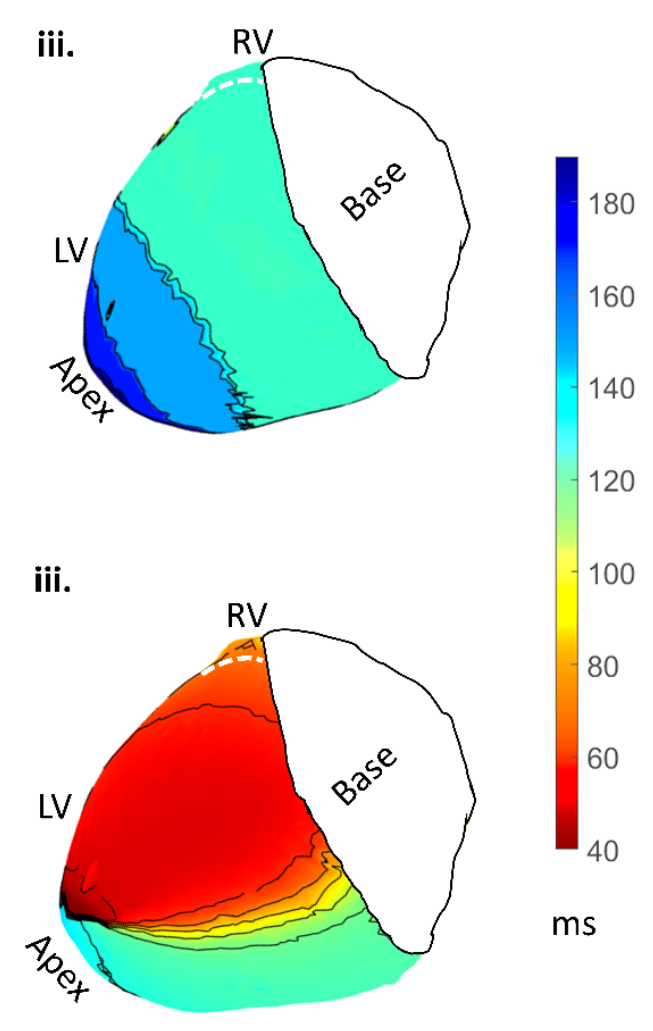


Figure 4:
A.
Anterior
i.

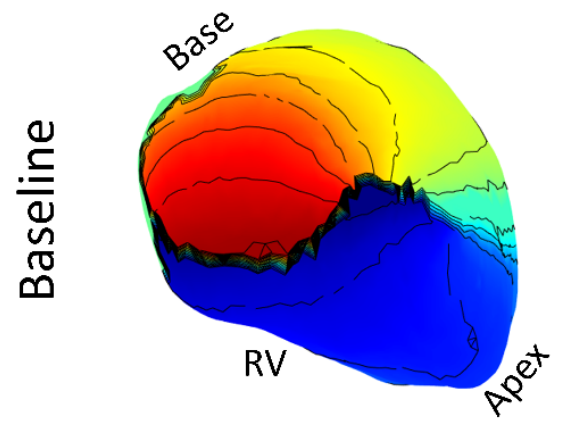
B.

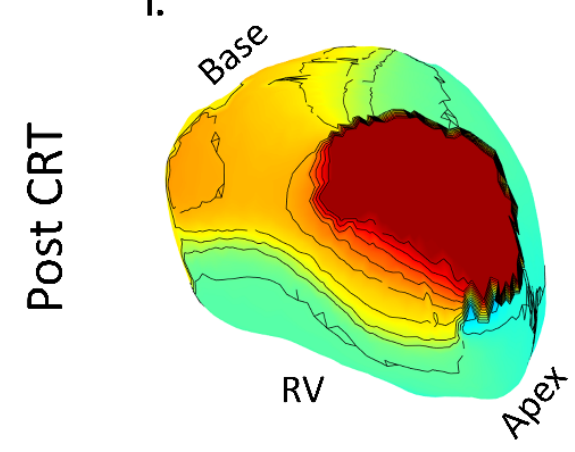
Left lateral
ii.

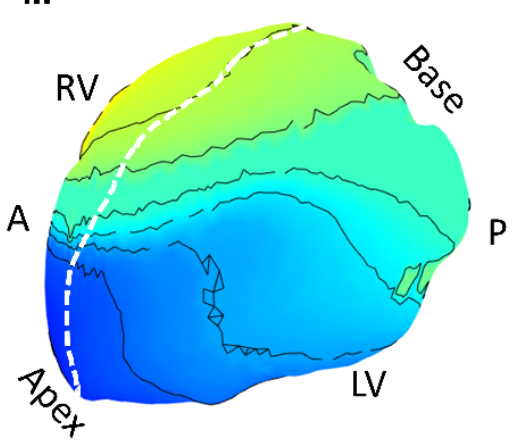
ii.

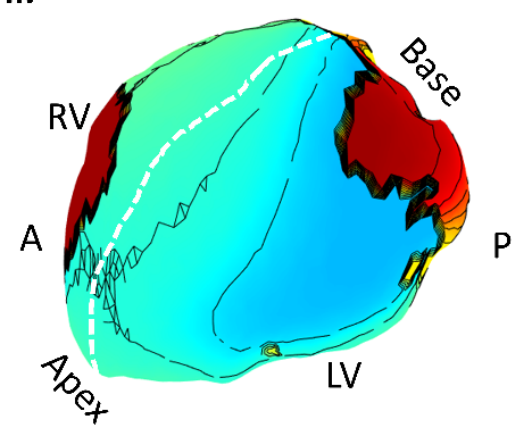
Posterior
iii.

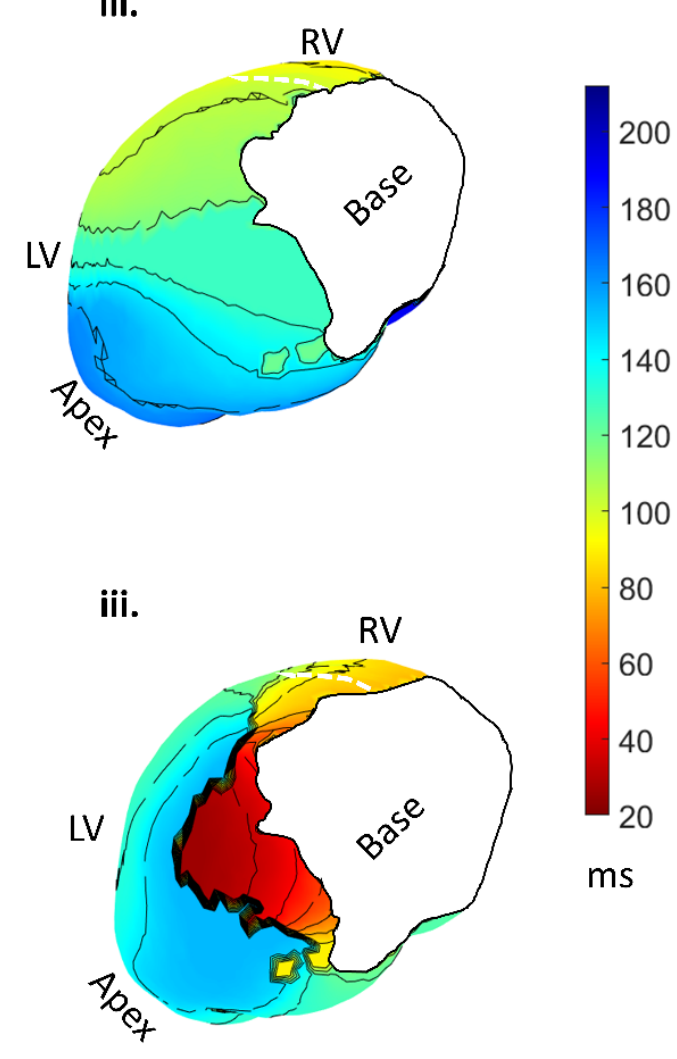


Figure 5:
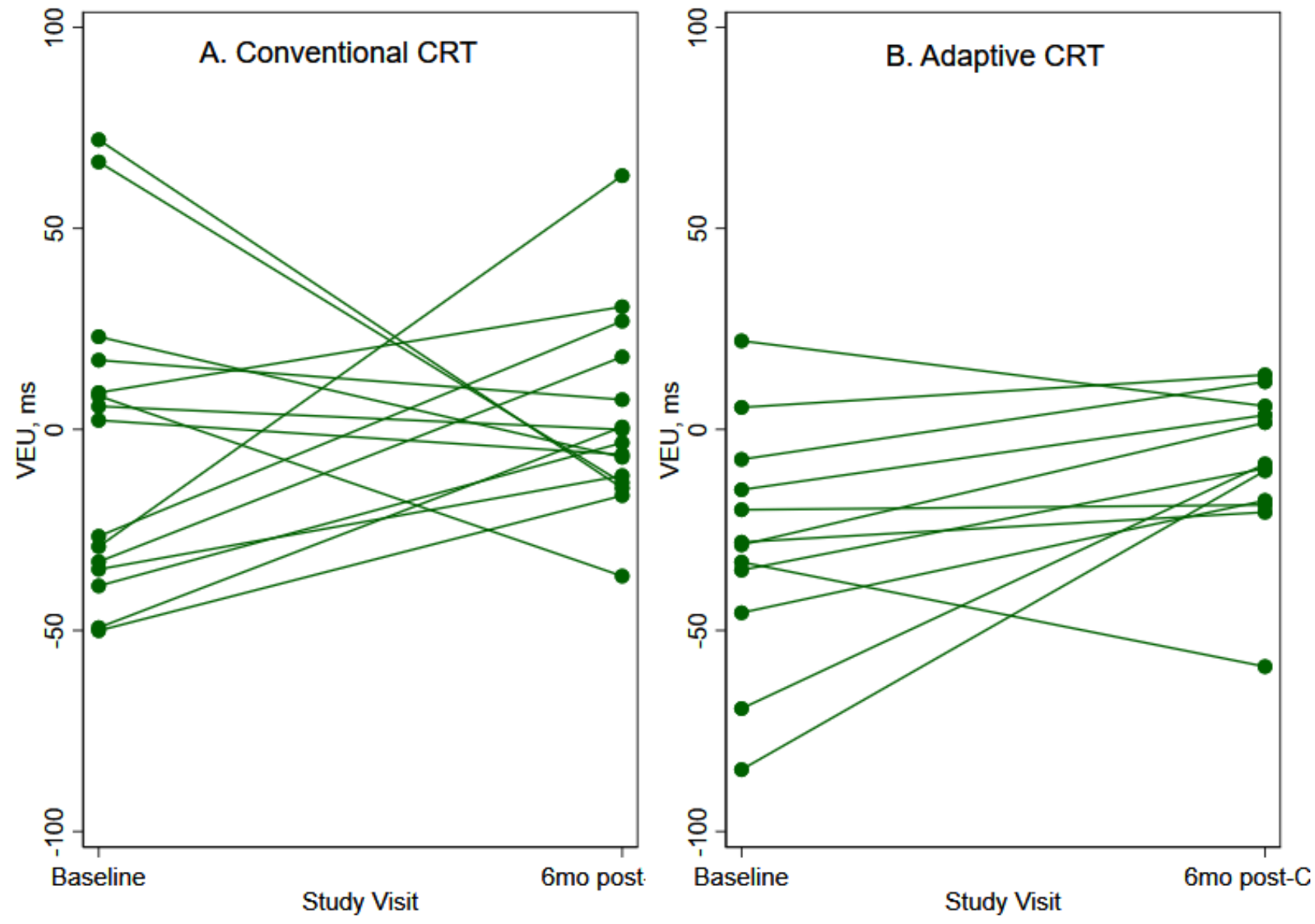


\section{Supplemental Material}

Supplemental Table 1. Correlation matrix for baseline (n=32) electrical dyssynchrony metrics measured on the reconstructed epicardial activation map and body surface ECG.

\begin{tabular}{|c|c|c|c|c|}
\hline & \multicolumn{4}{|c|}{ Spearman's $\rho$ coefficient } \\
\hline & VEU & EDIV & $\mathrm{EDI}_{\mathrm{LV}}$ & $\mathrm{EDI}_{\mathrm{RV}}$ \\
\hline QRS duration & 0.059 & 0.334 & 0.267 & 0.241 \\
\hline P-value & 0.752 & 0.062 & 0.140 & 0.283 \\
\hline QRS area & -0.047 & 0.091 & 0.261 & -0.114 \\
\hline P-value & 0.797 & 0.622 & 0.150 & 0.536 \\
\hline SAIQRST & 0.021 & 0.120 & 0.175 & 0.037 \\
\hline P-value & 0.908 & 0.064 & 0.340 & 0.839 \\
\hline
\end{tabular}


medRxiv preprint doi: https://doi.org/10.1101/2020.09.14.20194415; this version posted September 15, 2020. The copyright holder for this preprint (which was not certified by peer review) is the author/funder, who has granted medRxiv a license to display the preprint in perpetuity.

Supplemental Figure 1 Approximation of standard 12 lead ECG location on from 128-lead electrode position. Black dots- Approximated location of precordial V1-V6 electrodes. Yellow dots - noise-free body surface mapping electrodes. Blue circled yellow dots indicated 6 nearest electrodes approximated the V1-V6 lead location of standard 12-lead ECG.

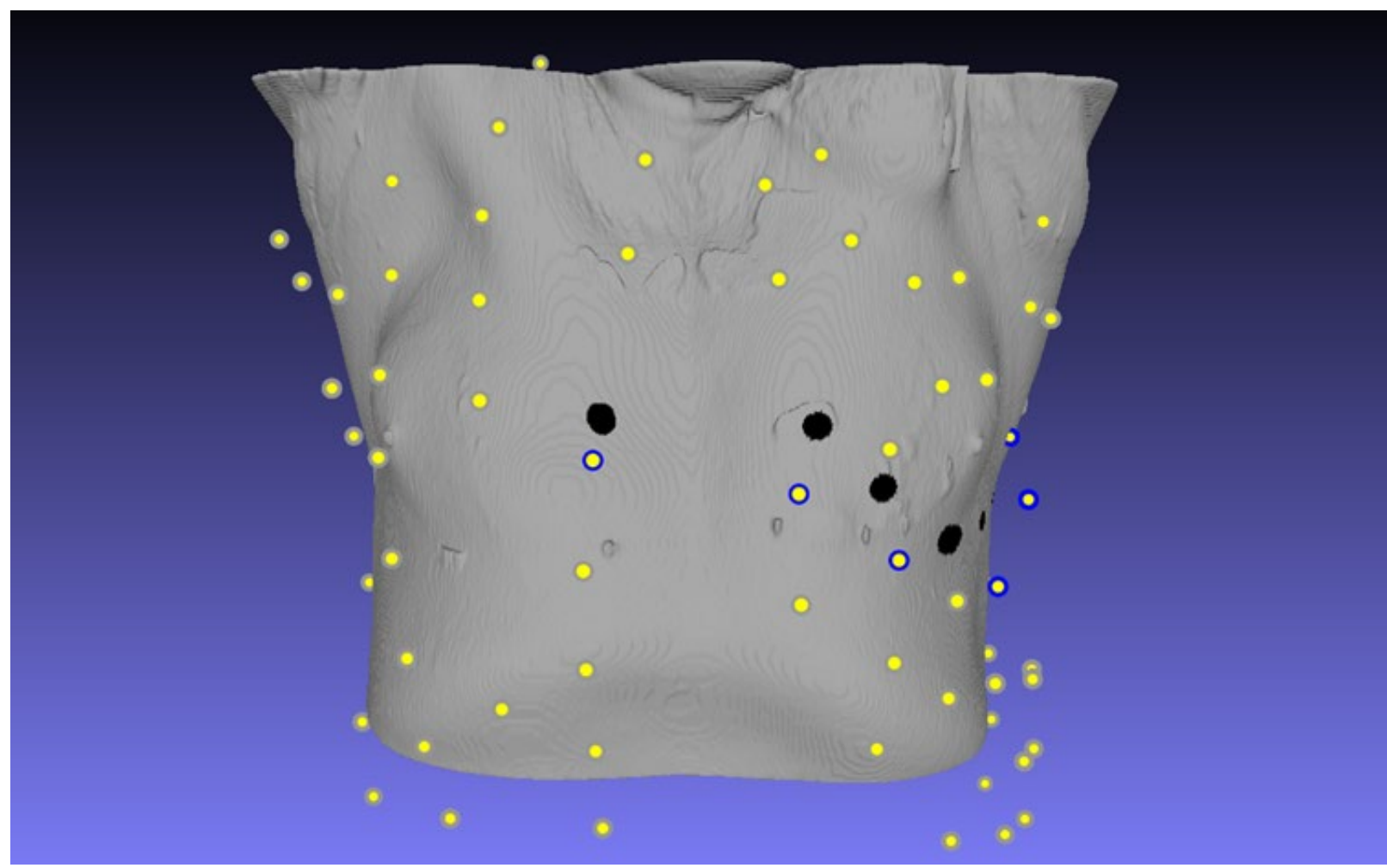




\section{Supplemental Figure 2. A representative example of a typical LBBB in a female study participant with nonischemic}

cardiomyopathy (the corresponding map is shown in Figure 3A).

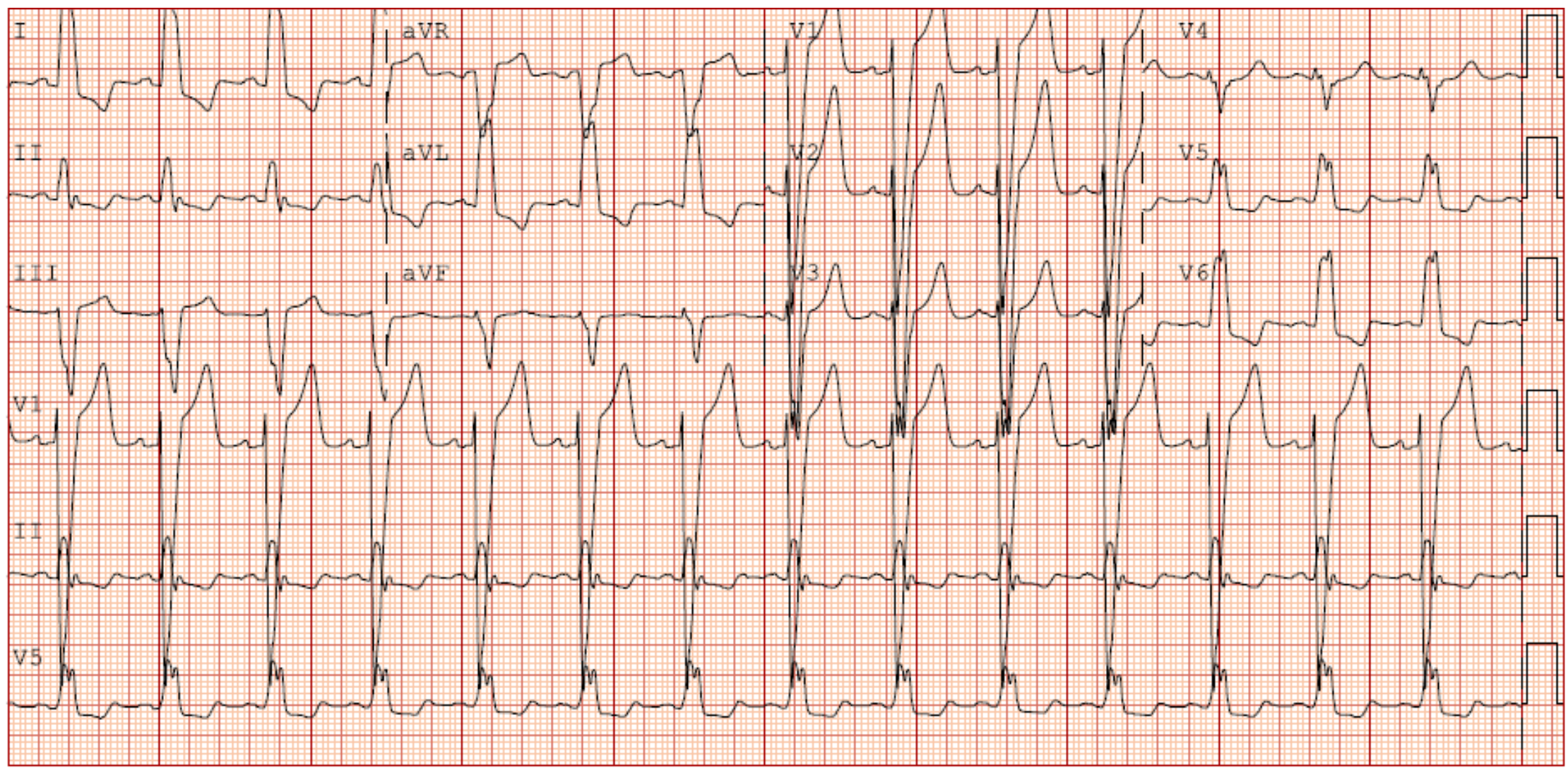




\section{Supplemental Figure 3. A representative example of interventricular conduction delay (atypical LBBB) in a female study}

participant with nonischemic cardiomyopathy (the corresponding map is shown in Figure 4A).

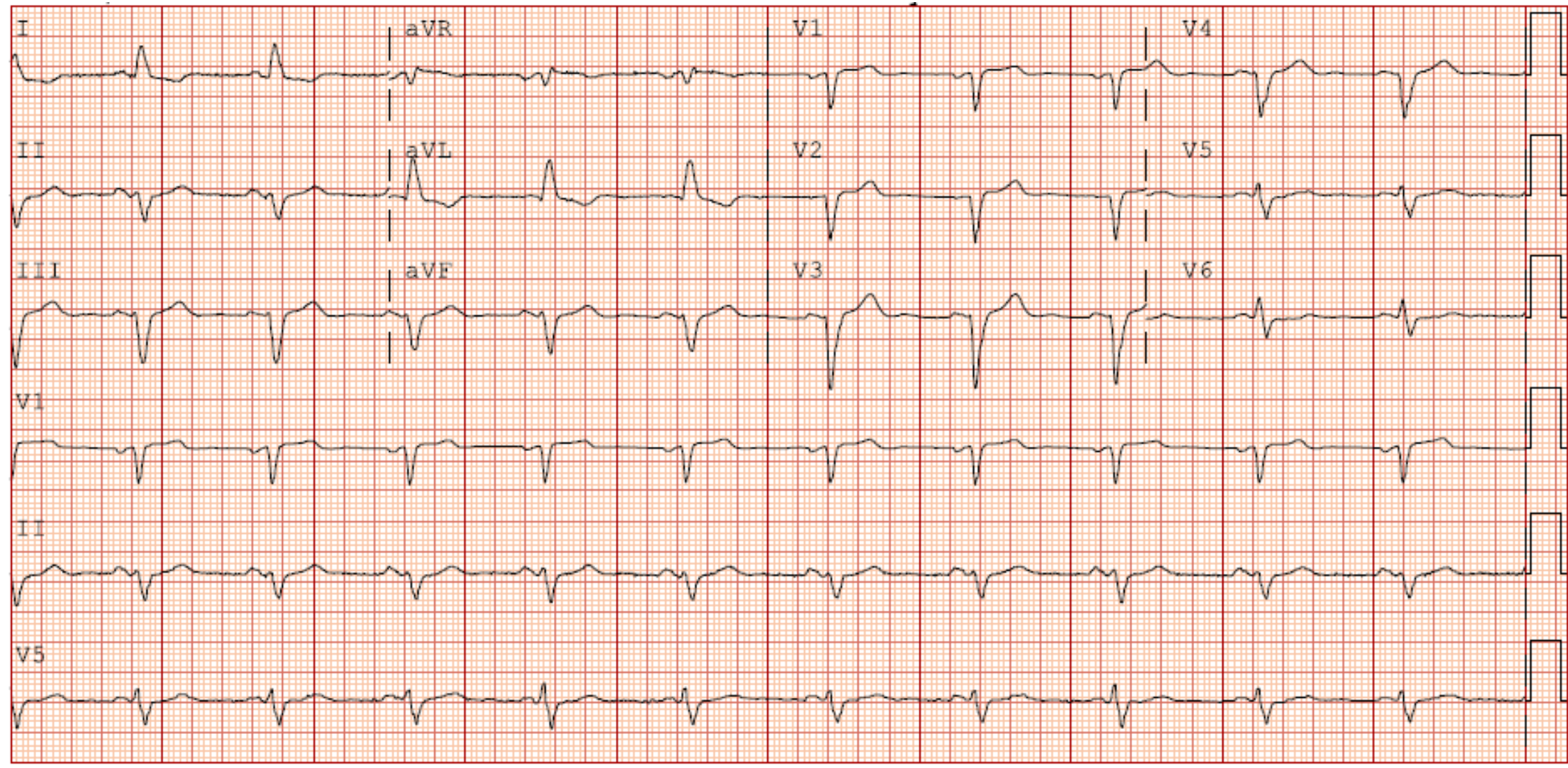

